\title{
PENGARUH PEMANFAATAN FASILITAS BELAJAR TERHADAP MUTU LAYANAN AKADEMIK PROGRAM STUDI DI SEKOLAH PASCASARJANA UNIVERSITAS PENDIDIKAN INDONESIA
}

\author{
Oleh \\ Khairul Azan \\ STAIN Bengkalis \\ khairulazan18@gmail.com
}

Diterima 25 Juli 2018, direvisi 26 Juli 2018, diterbitkan 31 Agustus 2018

\begin{abstract}
One of the efforts to improve the quality of higher education is to provide excellent service on the academic needs of each student as a user (customer) of service college. Several factor which effect the quality of academic services include adequate learning facilities in terms of services that fit the student needs. This research is motivated by the gap between empirical phenomena and the prevailing theory, where student often do not feel satisfied with the quality of academic services provided, such as facilities are not in accordance with the expectations of students as cutomers. This study aims to describe and analyze the effect of learning facilities utilization towards quality of academic services for study program at the School of Postgraduate Studies Indonesia University of Education. The methode used in this study is a survey methode with a quantitative approach. The data collection technique used is a questionnaire. The sampled-subject are students from 36 existing courses at the School of Postgraduate Studies Indonesia University of Education amounting to 352 student. The result show that the general picture of the quality of academic services for study program at School of Postgraduate Studies Indonesia University of Education are in the category. As for the use of learning facilities in the fairly well category. Utilization of the facilities have a significant influence on the quality of academic services for study program.
\end{abstract}

Keywords: Pemanfaatan Fasilitas Belajar, Mutu Layanan Akademik Program Studi 


\section{PENDAHULUAN}

Perguruan tinggi sebagai salah satu bagian dari sistem pendidikan nasional yang bergerak dibidang penyedia jasa pendidikan harus mampu merespon perubahan lingkungan yang disebabkan antara lain karena meningkatnya pengetahuan masyarakat sebagai customer (pelanggan) yang ditunjukkan dengan perubahan sikap yang semakin kritis, meningkatnya kompetisi, tuntutan dunia kerja yang semakin tinggi dan perubahan teknologi yang begitu pesat.

Perubahan ini membuat persaingan yang semakin tinggi diantara perguruan tinggi. Agar mampu bersaing dan tetap bertahan maka pengelolaan berbasis mutu merupakan faktor penentu. Beberapa komponen yang bisa mempengaruhi mutu sebuah perguruan tinggi. Salah satu diantaranya ialah mutu layanan pendidikan yang diberikan institusi kepada pelanggan (mahasiswa). Sebagaimana yang dijelaskan dalam Undang-Undang Penyelenggaraan Pendidikan Tinggi No. 12 tahun 2012 Pasal 6 yang menyebutkan salah satu prinsip penyelenggaraan pendidikan tinggi yaitu "pemberdayaan semua komponen masyarakat melalui peran serta dalam penyelenggaraan dan pengendalian mutu layanan Pendidikan Tinggi”.

Layanan adalah sebuah proses pemberian jasa (service delivery) dari pemberi layanan kepada pelanggan (customer). Kualitas layanan tidak bisa dinilai dari perspektif produsen tetapi harus beranjak dari perspektif customer yaitu kepuasan pelanggan. Kepuasan pelanggan merupakan cerminan dari layanan yang bermutu. Menurut Kotler (2000, hlm. 45), kepuasan dari sisi konsumen dipandang baik apabila memenuhi apa yang mereka harapkan, sebaliknya pelayanan akan dipersepsikan buruk apabila tidak memenuhi apa yang mereka harapkan. Penjelasan tersebut mengandung makna bahwa mahasiswa dalam hal ini sebagai pelanggan di perguruan tinggi akan mamadang mutu layanan sebagai perbandingan antara persepsi mereka tentang apa yang mereka terima dengan apa yang mereka harapkan.
Beberapa faktor yang dapat mempengaruhi kualitas layanan pendidikan (akdemik) yang diberikan pihak perguruan tinggi kepada mahasiswa. Hasil penelitian Astuti (2009, hlm. 11) menyebutkan tiga dimensi yang berhubungan dengan kualitas layanan dalam bentuk jasa pendidikan yaitu: (1) Respect for students (respek terhadap mahasiswa). Hal ini bisa berupa respon dalam bentuk layanan yang diberikan baik dari staf prodi maupun dosen kepada mahasiswa. Adapun layanan yang diberikan tersebut merupakan gambaran kinerja setiap individu. (2) Professor's knowledge (pengetahuan dosen), yang merupakan gambaran segala hal yang berkaitan dengan pengetahuan yang dipahami oleh dosen yang akan disampaikan kepada mahasiswa, dan (3) University physical environment (lingkungan fisik universitas atau perguruan tinggi), yang mencerminkan fasilitas-fasilitas yang tersedia baik di dalam ruang kuliah maupun di lingkungan kampus. Fasilitas yang ada di perguruan tinggi merupakan alat penunjang agar terciptanya proses pebelajaran yang efektif. Adapun yang tergolong fasilitas perguruan tingi diantaranya lahan kampus, parkir, bangunan, perpustakaan, toilet, ruang kelas, tempat ibadah, laboratorium, media pembelajaran dan lain-lain yang dianggap sebagai fasilitas di perguruan tinggi.

Dari penjelasan di atas jelaslah secara teoritis bahwa keberadaan fasilitas belajar berpengaruh terhadap kualitas dari layanan pendidikan (akademik) yang diterima mahasiswa. Namun, meskipun demikian fenomena yang terjadi dari gejala yang ditemukan terlihat adanya kesenjangan antara teoritis dan praktis. Meskipun telah mendapatkan setifikat mutu, mahasiswa seringkali merasa tidak puas dengan layanan akademik yang diberikan oleh perguruan tinggi diantaranya fasilitas yang masih belum sesuai dengan harapan dari para mahasiswa.

\section{METODE}

Penelitian ini menggunakan metode survei dengan pendekatan kuantitatif, dengan mengembangkan satu variabel independen 
(Pemanfaatan Fasilitas Belajar), dan satu variabel dependen (Mutu Layanan Akademik Prodi).

Penelitian ini dilakukan di SPs UPI dengan unit analisisnya semua Prodi yang ada di SPs UPI. Adapun subyek penelitiannya adalah mahasiswa dengan populasi semua mahasiswa yang masih aktif dari 36 prodi dengan jumlah 4.285 mahasiswa.

Untuk menentukan jumlah sampel penulis menggunakan dua tahapan yaitu : 1) mencari sampel dari total populasi dengan menggunakan teknik random sampling. 2) mencari jumlah sampel untuk masing-masing prodi dengan menggunakan teknik proporsional random sampling sehingga diperoleh 352 sampel sebagai responden.

Pengumpulan data primer dalam penelitian ini menggunakan angket yang berisikan pernyataan-pernyataan dengan lima alternatif jawaban (skala likert).

Untuk menganalisis pengaruh kausalitas antara variabel independen terhadap variabel dependen, dalam penelitian ini penulis membedakan dua kategori yaitu analisis deskriptif dan analisis hipotesis. Analisis deskriptif menggunakan rumus rata-rata (Weighted Means Scored) dari Furqon (2011, hlm. 42). Sedangkan analisis hipotesis menggunakan rumus regresi (Hartono, 2008, hlm. 178), dengan uji $t$ untuk hipotesis parsial, dan uji $F$ untuk hipotesis parsial.

\section{HASIL PENELITIAN DAN PEMBAHASAN}

\section{Hasil Penelitian}

Hasil analisis deskriptif menunjukkan bahwa secara umum variabel Y (Mutu Layanan Akademik Program Studi) di kategorikan tinggi, dengan skor rata-rata sebesar 3,58. Untuk variabel X (Pemanfaatan Fasilitas Belajar) di kategorikan cukup, dengan skor rata-rata sebesar 3,36.

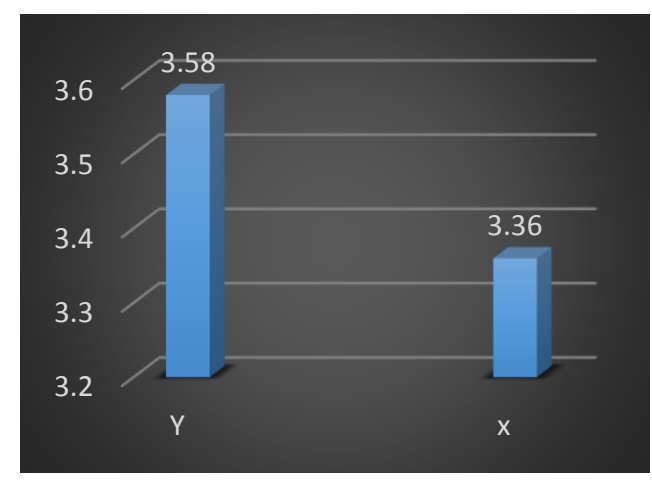

Gambar 2.

Rata-rata Setiap Variabel

Selanjutnya, hasil analisis koefisien korelasi ditemukan bahwa pengaruh variabel pemanfaatan fasilitas belajar terhadap mutu layanan akademik Program Studi sebesar 0,466 dengan koefisien determinasi 21,7\%.

Konstanta untuk masing-masing koefisien determinasi tersebut selanjutnya ditransformasi ke dalam persamaan regresi yaitu: $\mathrm{Y}=36,136+0,170 \mathrm{X}_{1}$

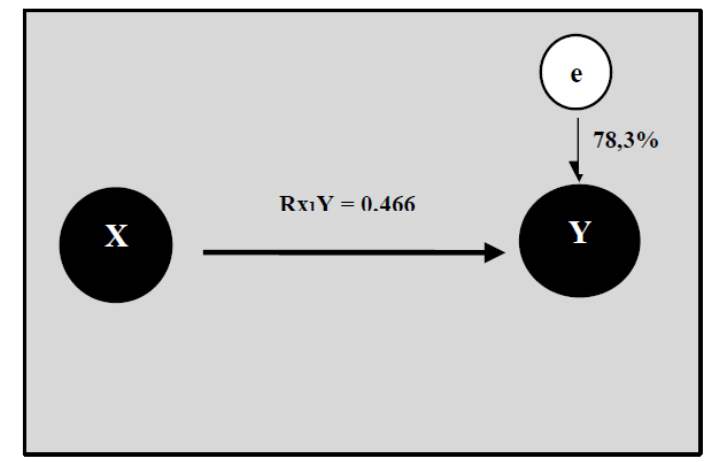

Gambar 3.

Struktur Pengaruh X Terhadap Y

\section{Pembahasan}

\section{Gambaran Mutu Layanan Akademik Program Studi (Y) di Sekolah Pascasarjana Universitas Pendidikan Indonesia}

Mutu layanan merupakan elemen penting dalam tercapainya pengelolaan pendidikan yang bermutu. Sebagai penyedia jasa, institusi perguruan tinggi dihadapkan dengan tuntutan harus mampu memberikan pelayanan prima kepada setiap pengguna (customer) jasa 
pendidikan. Sehingga dengan layanan prima (bermutu) tersebut diharapkan pelanggan akan merasa puas. Layanan prima yang diberikan tersebut tentunya dalam bentuk layanan kebutuhan akademik yang sesuai dengan kebutuhan mahasiswa sebagai pelanggan internal di perguruan tinggi. Sebagaimana yang dijelaskan Oldfield \& Baron (Shah, 2013, hlm. 76), "service quality in higher education from an organizational perspective and suggest that instead of focusing on what is important for students institutions should pay attention to what their students want". (kualitas layanan di pendidikan tinggi dari perspektif organisasi dan menyarankan bahwa alih-alih berfokus pada apa yang penting bagi lembaga mahasiswa harus memperhatikan apa yang siswa mereka inginkan).

Penelitian tentang mutu layanan akademik prodi ini dilakukan di Sekolah Pascasarjana Universitas Pendidikan Indonesia dengan jumlah responden 352 mahasiswa dari 37 program studi yang ada di SPs UPI. Dari hasil penelitian yang dilakukan diperoleh informasi yang menunjukan bahwa mutu layanan akademik Program Studi yang diberikan kepada mahasiswa di Sekolah Pascasarjana Universitas Pendidikan Indonesia sudah tinggi. Hal ini didasarkan pada hasil perhitungan rata-rata sebesar 3,58.

\section{Gambaran Pemanfaatan Fasilitas Belajar (X) di Sekolah Pascasarjana Universitas Pendidikan Indonesia}

Fasilitas belajar merupakan unsur penting dalam proses pendidikan. Meskipun bukan menjadi hal utama namun tanpa fasilitas yang memadai proses belajarmengajar juga tidak akan terlaksana dengan baik. Hal ini sejalan dengan pendapat Lawanson et al. (2011, hlm. 47), yang mendefisikan fasilitas belajar sebagi "school facilities can be defined as those things that enable the teacher to do his/her work very well and helping the learners to learn effectively". (fasilitas sekolah dapat didefinisikan sebagai hal-hal yang memungkinkan guru untuk melakukan/pekerjaannya dengan sangat baik dan membantu peserta didik untuk belajar secara efektif).

Penelitian tentang pemanfaatan fasilitas belajar ini dilakukan di Sekolah Pascasarjana Universitas Pendidikan Indonesia dengan jumlah responden 352 mahasiswa dari 36 program studi yang ada di SPs Universitas Pendidikan Indonesia. Dari hasil penelitian yang dilakukan diperoleh informasi yang menunjukan bahwa fasilitas belajar yang bisa dimanfaatkan oleh mahasiswa sebagai customer di Sekolah Pascasarjana Universitas Pendidikan Indonesia sudah bisa demanfaatkan dengan cukup baik. Hal ini didasarkan pada hasil perhitungan rata-rata sebesar 3,36.

\section{Analisis Pengaruh Pemanfaatan Fasilitas Belajar (X) terhadap Mutu Layanan Akademik Program Studi (Y) Pada Sekolah Pascasarjana Universitas Pendidikan Indonesia}

Hasil pegolahan data terkait pengaruh antara pemanfaatan fasilitas belajar terhadap mutu layanan akademik prodi diperoleh koefisen korelasi sebesar 0,466 di taraf signifikansi thitung $(9,853)>t_{\text {tabel }}(1,9)$. Hal ini menandakan bahwa terdapat pengaruh yang signifikan antara variabel $\mathrm{X}_{1}$ (pemafatatan fasilitas belajar) terhadap Y (mutu layanan akademik prodi) dan berada pada kategori cukup kuat. Pendapat tersebut didasarkan pada kategori yang berlaku dengan perolehan nilai $r_{\text {hitung }}$ sebesar 0,466 yang terletak pada interval $0,400-0,599$.

Adapun koefisien determinasi yang diperoleh dari penelitian ini adalah sebesar $21,7 \%$, sedangkan $78,3 \%$ dipengaruhi oleh faktor lain (epsilon). Hal ini sejalan dengan pendapat Sallis (2006, hlm. 192) yang mengemukakan beberapa faktor yang dapat mempengaruhi mutu layanan akademik yang tidak diteliti dalam penelitian ini, diantaranya faktor kepemimpinan, strategi, sistem, evaluasi, motivasi staf. 
Berdasarkan hasil analisis data tersebut maka hipotesis yang diajukan dalam penelitian ini yaitu "terdapat pengaruh antara pemanfaatan fasilitas belajar terhadap mutu layanan akademik" diterima. Hal ini juga didukung dengan beberapa hasil penelitian terdahulu diantaranya; yang dilakukan Saginova \& Belyansky (2008, hlm. 350), yang mengatakan bahwa upaya peningkatan layanan pendidikan harus didukung oleh inovasi dan pengembangan fasilitas pendidikan. Hal serupa diungkapkan Yeo (2008, hlm. 159), bahwa ia mengatakan upaya peningkatan mutu layanan harus didukung dengan tersedianya fasilitas yang dapat mendukung proses pembelajaran. Selanjutnya hasil penelitian Fernandes, et al (2013, hlm. 624) menjelasan bahwa fasilitas dan layanan yang diberikan merupakan komponen yang dapat menentukan loyalitas pelanggan. Lebih lanjut hasil penelitian Roberts (2006, hlm. 378) 5) juga menemukan bahwa ketersediaan

\section{SIMPULAN}

1. Mutu layanan akademik Program Studi yang meliputi indikator tangibles, emphaty, reliability, responsivenes, dan assurance berada pada kategori tinggi. Ini menggambarkan bahwa layanan yang diberikan kepada mahasiswa sudah bermutu.

2. Pemanfaataan fasilitas belajar yang meliputi indikator efektivitas dan efisiensi berada pada kategori cukup. Ini dapat dipahami bahwa pemanfaatan fasilitas belajar sudah berjalan dengan cukup baik.

3. Pemanfaatan fasilitas belajar berpengaruh signifikan terhadap mutu layanan akademik Program Studi di Sekolah Pascasarjana Universitas Pendidikan Indonesia.

\section{DAFTAR PUSTAKA}

Ahmed, R, \& Ali, I. S. (2012). "Implementing TQM Practices in Pakistan Higher Education Institutions". Pak. j. eng. technol. sci. Vol. 2. (1), 1-26. fasilitas sekolah berhubungan terhadap lingkungan belajar. Disamping itu hasil penelitian Uline dan Moran (2008, hlm. 55) juga mengungkapkan bahwa kualitas fasilitas memiliki hubungan terhadap prestasi mahasiswa. Lebih jauh lagi Mahajan, et al (2014, hlm. 392), dalam hasil penelitiannya juga mengutarakan hal yang sama yang menunjukkan bahwa beberapa faktor yang dapat mempengaruhi mutu pendidikan diantaranya adalah infrastruktur. Tentunya infrastruktur yang dimaksud ialah tersedianya fasilitas belajar yang memadai. Hal ini sejalan dengan pendapat Nadiri (Fernandes, et al., hlm. 618) mengungkapkan bahwa ketersedian fasilitas fisik seperti ruang kelas dan bangunan memberikan pengaruh positif terhadap kepuasan dari mahasiswa.

Arum, A. S.W. (2007). Manajemen Sarana dan Prasarana Pendidikan. Jakarta: MKM.

Balakrishnan, S. M. W. S. (2013). Assessing Student Satisfaction in Transnational Higher Education. International Journal of Educational Management. Vol. 27. (2), 143-156.

Barnawi \& Arifin, M. (2012). Manajemen Sarana dan Prasarana Sekolah. Jogjakarta: Ar-Ruzz Media.

Blandford, Sonia. (2000). Managing

Chong, S.Y \& Ahmed, P. (2014). A Phenomenology of University Sercive Quality Experience. International Journal of Educational Management. Vol. 28. (1), 36-52.

Daryanto \& Farid, M. (2013). Konsep Dasar Manajemen Pendidikan di Sekolah. Yogyakarta: Gava Media.

Fernandes, C., et al. (2013). "Understanding Student Satisfaction and Loyalty in the UAE HE Sector". International Journal of Educational Management. Vol. 27. (6), 613-630.

Furqon. (2011). Statistik Terapan untuk Penelitian. Bandung: Alfabeta. 
Hartono. (2008). Statistik Untuk Penelitian. Yogyakarta : Pustaka Pelajar.

Hoy, Charles., et al. (2000). Improving Quality in Education. London: Falmer Press.

Kotler, P. (2008). Marketing Management. New Jersey: Prentice Hall Inc.

Lawanson, et al. (2011). "Provision and Management of School Facilities for the Implementation of UBE Programme". Journal of Educational and Social Research. Vol. 1. (4), 4755.

Lovelock, C \& Wright, L. (2002). Principle of service marketing and management. New Jersey: Prentice Hall Inc.

Mahajan, R., et al. (2014). "Factors Affecting Quality of Management Education in India". International Journal of Educational Management. Vol. 28. (4), 379-399

Min, Sein \& Khoon, C.C. (2013). "Demographic Factors in the Evaluation of Service Quality in Higher Education: International Students' Perspective". international Review of Management and Business Research. Vol. 2. (4), 994-1010.

Minarti, Sri. (2011). Manajemen Sekolah (Mengelola Lembaga Pendidikan Secara Mandiri). Jogjakarta: Ar-ruzz Media.

Mosahab, R., et al. (2010). "Service Quality, Customer Satisfaction and Loyalty: A Test of Mediation". International Business Research. Vol. 3. (4), 72-80.

Naik, K. N. C., et al. (2010) "Service Quality (Servqual) and its Effect on Customer Satisfaction in Retailing". European Journal of Social Sciences. Vol. 16. (2), 231-243.

Rasli, et al. (2012). "Perception of Service Quality in Higher Education: Perspective of Iranian Students in Malaysian Universities ". International Journal of Academic Research in Management (IJARM). Vol. 1. (1), 10-25.

Roberts, W.L. (2009). "Measuring School Facility Conditions: an illustration of the Importance of Purpose". Jurnal Educational Administration. Vol. 47. (3), 368-380.

Rohiat. (2010). Manajemen Sekolah. Bandung: PT. Refika Aditama.

Saginova, O \& Belyansky, V. (2008). "Facilitating Innovations in Higher education In Transition Economies". International Journal of Educational Management. Vol. 22. (4), 341-351.

Sallis, Edward. (2006). Total Quality Management in Education (Manajemen Mutu Pendidikan). Jogjakarta: IRCiSoD.

Shah, T. F. (2013). "Service Qualtiy and Customer Satisfaction in Higher Education in Pakistan". Journal of Qulity and Technology Management. Vol. IX. (IX), 73-89.

Tjiptono, F. (2004). Manajemen Jasa. Yogyakarta: ANDI.

Undang-Undang Pendidikan Tinggi No. 12 tahun 2012.

Uline, C \& Moran, T.M. (2008). "The Walls Speak: the Interplay of Quality Facilities, School Climate, and Student Achievement". Jurnal of Educational Administration. Vol. 46. (1), 55-73.

Wang, M. I \& Shieh, J. C. (2006). "The relationship between service quality and customer satisfaction : The Example of CJCU Library". Journal of Information \& Optimization Sciences. Vol. 27. (1), 193-203.

Wilkins, S dan Balakrishnan, S.M. (2013). "Assessing Student Satisfaction in Transnational Higher Education". International Journal of Educational Management. Vol. 27. (2), 143-156.

Wulandari, D. A., \& Juliawan, I. N. (2018). Peningkatan Mutu Pembelajaran Agama Hindu Dalam Mewujudkan Perubahan Mental Siswa. Jurnal Penjaminan Mutu, 4(1), 7-19.

Yeo, R. K. (2008). "Servicing Service Quality in Higher Education: Quest for Excellence". On the Horizon. Vol. 16. (3), $152-161$ 